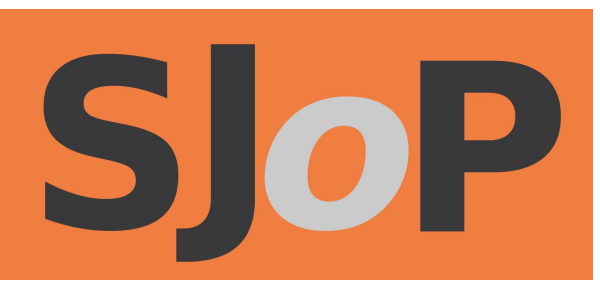

Symposium abstracts: Pace, penalty and pirouette: the sociology of physical culture

\author{
VICTORIA PALMER \& BETHANY WHITESIDE; \\ EMMANUELLE TULLE; URSULA M. BURGER, \\ ELAINE THOMSON \& ELENI THEODORAKI; \\ JAMES BOWNESS; CONOR HEFFERNAN; \\ LAURA BISSELL \& DAVID OVEREND; \\ VANESSA COFFEY; LITO TSITSOU; KIRSTY KAY; \\ SUE SMITH; LUCY AMSDEN; HANDE GÜZEL; \\ ANDRIA CHRISTOFIDOU; JOSEPHINE LEASK
}

The Scottish Journal of Performance

Volume 2, Issue 1; December 2014

ISSN: 2054-1953 (Print) / ISSN: 2054-1961 (Online)

Publication details: http://www.scottishjournalofperformance.org

To cite this article: Palmer, V. and Whiteside, B. et al., 2014. Symposium abstracts: Pace, penalty and pirouette: the sociology of physical culture. Scottish Journal of Performance, 2(1): pp.87-103.

To link to this article: http://dx.doi.org/10.14439/sjop.2014.0201.05

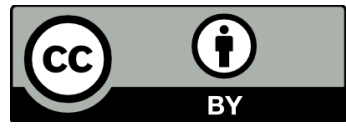

This work is licensed under a Creative Commons 


\title{
Pace, penalty and pirouette: the sociology of physical culture
}

\author{
SYMPOSIUM ABSTRACTS:
}

VICTORIA PALMER \& BETHANY WHITESIDE; EMMANUELLE TULLE; URSULA M. BURGER, ELAINE THOMSON \& ELENI THEODORAKI; JAMES BOWNESS; CONOR HEFFERNAN; LAURA BISSELL \& DAVID OVEREND; VANESSA COFFEY; LITO TSITSOU; KIRSTY KAY; SUE SMITH; LUCY AMSDEN; HANDE GÜZEL; ANDRIA CHRISTOFIDOU; JOSEPHINE LEASK

DOI: 10.14439/sjop.2014.0201.05

Publication date: 16 December 2014

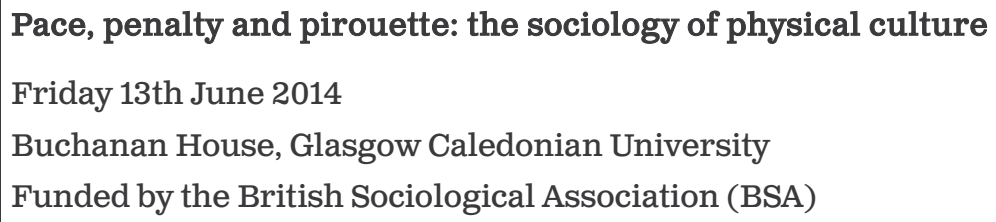

Pace, penalty and pirouette: the sociology of physical culture was an event organised and hosted by PhD students Victoria Palmer (Glasgow Caledonian University) and Bethany Whiteside (Royal Conservatoire of Scotland). Funded by the British Sociological Association as a Postgraduate Regional Event, the day was primarily designed to be a supportive platform for postgraduate students from across Scotland and further afield to unite, discuss, present, and share their research with academics with similar interests. The event focused on aspects of 'physical culture', attracting scholars from several areas of study including dance, leisure studies, outdoor activity, physical activity, physical education, physical theatre, outdoor activity and sport. Broadly speaking, those who study physical culture are interested in the ways in which individuals engage in (or do not engage in) physical practices and how these individuals are affected 
by, or influence their social and cultural environment.

The event aimed to explore and unite the various practices of physical culture and to interrogate how they intersect with sociological issues such as ageing, class, disability, gender and race. Moreover, an uneasy relationship has traditionally existed between sport and dance, with the latter often subsumed into the former in myriad ways (for example, through the necessary physicality and the adoption of competition formats). However, as this event demonstrated, the methodologies and approaches adopted across these disciplines highlight the compatibility between them when the focus is on the moving body.

Through a formal review process, eleven speakers were invited to present their research from institutions across the UK and Europe. Structured around three panels focusing on 'Sport and Physical Activity', 'Dance and Physical Theatre' and 'Gender and Physical Culture', scholars spoke about such diverse subjects as the place of white masculinity in the fitness arena of 1930s and 1940s America (Conor Heffernan), 'body-mapping' as a technique in physical theatre devising (Vanessa Coffey) and the concept of the 'ridiculous' in clown performance (Lucy Amsden). In addition, we were delighted to be joined by two keynote speakers: Dr Emmanuelle Tulle (Glasgow Caledonian University) focused on the portrayal of ageing elite athletes in the media and Dr Laura Bissell (Royal Conservatoire of Scotland) presented on the exploration and framing of the daily commute as 'Rhythmanalysis' (Lefebvre, 1992).

\section{VICTORIA PALMER \& BETHANY WHITESIDE}


EMMANUELLE TULLE

\section{In Search of Lost Times or Time Regained? Numbers and ambiguous narratives of ageing in media reports of elite athletes}

The presentation will engage reflexively on the ambiguity of the scientific project which on the one hand provides the means to more effectively develop physical capital, offering the promise of time regained via anti-ageing pronouncements, and on the other hand contributes to the discourse of ageing as decline. To explore this conundrum I will focus on two high-profile male athletes-Lance Armstrong and Roger Federer-and show how their ageing is foretold in media and personal accounts of their achievements. What is striking in these documents is how numbers and a specific conception of time informed by science are deployed to construct a truth of the athletes' elite status as well as their ageing. The athletes are prematurely aged and subjected to the dominant discourse of ageing and old age as decline, which puts their reputational capital at risk. Supported by Foucauldian theoretical and conceptual tools, the analysis reveals strategies the athletes themselves use to attempt to protect their reputation, their futures and social position. Two narratives emerge: one of active retirement which is described as socially desirable (Lance Armstrong), and a narrative foregrounding of age as a positive process of discovery (Roger Federer).

DR EMMANUELLE TULLE is Reader in Sociology at Glasgow Caledonian University. She has over 15 years' experience of conducting research in old age, with a particular focus on understanding and theorising how older people make sense of, and manage, the process of bodily ageing from a cultural perspective. The research underpinning her theoretical and conceptual development has focused on Master athletes and their experiences of ageing in sport, symptomatic older people who engage in regular physical activity, and media reporting of the ageing of professional elite athletes. She has also cast a critical eye on the legacy implications of large sporting events and the role of sport science in legitimating the turn to physical activity in later life. Tulle is currently examining the science of sedentary behaviour and is the author of a monograph, 
Ageing, the Body and Social Change: Running in Later Life (Palgrave, 2008) and with Dr Cassie Phoenix is currently co-editing a collection entitled Physical Activity and Sport in Later Life: Critical Approaches.

\section{URSULA M. BURGER, ELAINE THOMSON \& ELENI THEODORAKI}

\section{Marketing women's sports grrrl style: a feminist analysis of advertising, commoditisation and identity in roller derby}

Brace-Govan (2010) cites Hirschman and Stern (2000) to argue that the advertising discourse of the athletically active female has an important effect on women consumers 'through the creation of ideal, or aspirational, kinds of femininity which can be viewed and imagined by all women' (p.371). From a feminist perspective, this discourse is problematic due to its pre-occupation with the inequity of the sexes in all aspects of life, and the negative impact certain depictions of femininity can have on female body issues (Gill, 2008). Riot grrrl is a branch of third wave feminism (Gillis et al., 2007) that has been positioned against mainstream patriarchal culture. Peaking in the mid1990s, its proponents expressed their anger at inequality via the (ephemeral, postmodern) medium of zines (selfproduced and distributed print magazines) and punk music (Dunn \& Farnsworth, 2012; Feigenbaum, 2007). In a postmodern world of global capitalism, most aspects of life have become commodified and marketing communications now have a fundamental cultural role to play (Shankar et al, 2009). Using the example of roller derby, an emerging female, full-contact, grassroots sport (Breeze, 2010; Finley, 2010; Pavlidis, 2012), in combination with the tenets of selfsufficient and independent production of female voices of the riot grrrl movement, this study explores the connections between roller derby's alternative character and the riot grrrl characteristics of its marketing communications output. The aim of this paper is to draw a connection between these two different women-powered outlets through analysing programmes, websites, and blogs of UK 
roller derby leagues and comparing them to the riot grrrl zine productions.

URSULA BURGER is a postgraduate research student at Edinburgh Napier University's School of Marketing, Tourism and Languages.

DR ELAINE THOMSON is a lecturer in Marketing at Edinburgh Napier University's School of Marketing, Tourism and Languages.

DR ELENI THEODORAKI is a reader in Festival and Event Management at Edinburgh Napier University's School of Marketing, Tourism and Languages.

\section{JAMES BOWNESS}

\section{Ageing, identity and gender in the Masters sports movement}

An ageing population and an unfettered societal exultation regarding sport and its benefits have resulted in a new phenomenon, the Masters athlete. An increasing level of agency has cultivated the practices of middle age and extended the period before the often undesired old age. Successful ageing, a natural precursor to medical discourse, consumer culture and capitalist ways, is in vogue in our current times. Masters athletes are the pioneers of successful ageing, radicals opposed to social disengagement and frailty commonly associated with biological ageing. Much academic work has been done on the structural influences which generate such dispositions. However, more work is needed in understanding the effects of ageing on the identity of an athlete, how they fit into the aged social field and how they encounter societal marginalisation. To illuminate such theoretical queries, an interesting group of athletes will be utilised. Masters athletes involved in the Highland games movement will meet in Inverness this September for the World Highland Games gathering, an event steeped in masculine identity. How do older women experience these practices, being both deviant to the 
stereotypes of their age and their gender? Furthermore, research into physical activity and age has found strong links between increased levels of activity and prolonged longevity. How do the Highland games athletes experience mundane tasks and how has their participation in a highly strength-based event aided their successful ageing? This presentation aims to answer these questions and more.

JAMES BOWNESS is a PhD student within the Social Sciences and Media Journalism department, part of the Glasgow School of Business and Society at Glasgow Caledonian University. His research interests surround the sociology of sport and in particular, the various avenues of ageing research.

\section{CONOR HEFFERNAN}

\section{Charles Atlas and American physical culture in the early twentieth century}

Fitness and the fitness industry are relatively unmined topics for historical research. Such research as exists tends to focus on biographies of famous figures in the industry, rather than the analysis of societal trends and identity formation. I intend to juxtapose both approaches. In the early twentieth century, Charles Atlas and his business partner Charles Roman created a mail order workout course that continues to this day and has had over thirty million customers. By focusing on the early years of the Atlas business, specifically 1929 to 1948 , I look at what the success of Atlas's business tells us about constructions of white masculinity during this time, along with exploring what Atlas's business meant for American physical culture. I contend that Atlas's business came at a profound juncture in US history during which there was a perceived crisis of white masculinity by both the public and elites. Atlas's business was successful because it asseverated that it could provide qualities men believed they needed and wanted at this time. In arguing this, I will firstly give a brief historical background to establish the crisis of masculinity that 
existed. Atlas and Roman themselves will be studied briefly to establish their public personae. The product, and more importantly its advertising, is studied to elucidate the marketing campaign utilised. Lastly, I examine the qualities which Atlas's product purported to provide, namely a sense of control, increased sexual vigour and attractiveness, and a strong personality. Such qualities, it is argued, were taken to represent the cornerstones of American white masculinity at this time in response to a perceived crisis of masculinity.

CONOR HEFFERNAN has recently completed a bachelor's degree in History and Political Science at Trinity College, Dublin. His historical interests focus primarily on health and fitness and American culture in the twentieth century, but also includes areas such as consumption politics in Nazi Germany and identity formation in Zaire. He plans to enter postgraduate research next year.

\section{LAURA BISSELL \& DAVID OVEREND}

\section{Rhythmic routes: developing a nomadic physical practice for the daily commute}

How can the contemporary performance practitioner maintain a deterritorialised, nomadic existence within the regulated systems of twenty-first century mobile life? Elliott and Urry (2010) argue that "life "on the move" appears to unfold faster and faster in the early days of the twenty-first century, as people become more reliant upon interdependent, digitised systems'. In contrast, the nomad is an aspirational figure, 'cut free of roots, bonds and fixed identities' (Pearson, 2010). Responding to the increasingly globalised context of mobilities and Braidotti's (2011) notion of 'becoming-nomad', this keynote asks whether nomadism can offer an alternative to the physical cultures created through the systemisation and repetition of everyday journeys.

This keynote introduces and reflects on an ongoing collaborative research project by Laura Bissell and David 
Overend. Focussing on the everyday rhythms of commuting, this practice-based enquiry uses Lefebvre's Rhythmanalysis (1992) to explore the interrelatedness of time and space in the routines of our everyday journeys. Rejecting conventional narratives of the 'weary and dystopian commuter' (Edensor, 2011), Overend and Bissell aim to develop a series of performative interventions that reimagine commuting as a creative and productive embodied practice with the potential for nomadic disruptions to the routines and rhythms of our everyday journeys.

DR LAURA BISSELL is a lecturer in Contemporary Performance Practice within the School of Drama at the Royal Conservatoire of Scotland. Laura is a visiting lecturer on the MRes in Creative Practices programme at the Glasgow School of Art and has presented her research on contemporary practices at conferences nationally and internationally.

DR DAVID OVEREND is a freelance director and lecturer in contemporary theatre and performance at the University of the West of Scotland. He trained at the Royal Academy of Dramatic Arts and was associate artist at the Arches, Glasgow (2007-2010). His current research focuses on performance and mobilities.

\section{VANESSA COFFEY}

\section{A mind of its own: accessing the unconscious through physical movement}

This presentation will focus on documentary and physical theatre specifically devised on the basis of narratives from mental health service-users, particularly using a technique known as 'body-mapping'. In the first instance, I am interested in how people perform their own stories physically, when overcoming trauma or dealing with day-today lived experience of mental health conditions. In the second, I am interested in how others can truthfully represent these stories. 
Does the use of dance or physicality in the presentation of mental health narratives interfere with what the audience understands to be 'truthful' on stage? Can using a recent Finnish study (Nummenmaa et al., 2013) on body topography and somatosensory memory help us to physically portray emotion?

VANESSA COFFEY is a theatre-maker who makes work through her company Down the Rabbit Hole, which focuses on mental health issues using physical theatre. In addition to the work she undertakes with her company, Vanessa also works independently as an actor, dancer, choreographer and dramaturg. Vanessa teaches at the Royal Conservatoire of Scotland in several capacities: as a tutor on the Masters (Acting) programme, a tutor on the undergraduate Acting degree, as well as teaching young people from the age of five through to adults in the Short Courses programmes through the Conservatoire, particularly the Junior Conservatoire of Drama's movement modules.

She was also employed by Sense Scotland as a drama tutor where she worked with adults with profound mental health concerns, and physical and learning disabilities. Her undergraduate degrees are in Law and French and she has a specific interest in the ethics of performance.

\section{LITO TSITSOU}

\section{Deconstructing talent in theatrical dance}

This paper will deconstruct the meaning of talent in ballet and contemporary dance in an attempt to overcome the myth of gift. Utilising a historical and empirical approach unified through the lens of the Bourdieusian field (Bourdieu, 1993), I will argue that any field of physical activity measures ability and talent with reference to internal field criteria, which are historically and socially shaped. Specifically, talent in theatrical dance is correlated with specific bodily ideal types and the ability for expression or expressivity primarily through the body. Further, talent is linked to musicality and rhythm. This paper argues that very often these are attributes passed on from teachers and 
the exposure of the body to other bodies. Similarly, such exposure constitutes a form of conditioning that determines both physical ability and expression. Finally it is argued that, above and beyond all, talent is constructed through economic and cultural capital that allows for the introduction of bodies in dance.

DR LITO TSITSOU is a former dancer and currently a researcher and teaching assistant at the School of Social and Political Sciences at the University of Glasgow. She obtained her PhD from the University of Glasgow during which she examined the social and aesthetic conditions of possibility of ballet and contemporary dance production, drawing on historical material from the West and on an empirical comparative investigation of dance in Greece and the UK. Lito focused on the class origins of dance practitioners, phenomena of institutional power and aesthetic tensions as interwoven in the politics of dance in different social contexts. Her current interests revolve around the making of the dancing body, disability and dance, and the social theory of Pierre Bourdieu.

\section{KIRSTY KAY}

\section{Folk dance and embodied national identity: a Scottish and Hungarian comparison}

This paper is a comparison of Scottish Cèilidh and Hungarian Táncház folk dance movements as they relate to national identity construction. Folk traditions provide premodern ties to geographic regions and a subsequent cultural-historical backbone to ideas of the nation-state. These two case studies will be used to reassess binary assumptions of two different 'types' of nationalism: Western Civic and Eastern Ethnic, critiquing the notion that ethnocultural forms are in some way antithetical to a liberal democratic society. In researching the two folk dance revivals this paper will reflect on recent scholarship of national identity formation as a reaction to, and resistance against, external ruling elites. Scotland and Hungary both experienced a folk revival in the early twentieth century in the face of rapid modernisation, which subsequently became aligned with more civic political ideas of the nation. 
Folk dance places the body at the centre of debates around nationalism. After increased political autonomy in the 1990s (Hungary's transition to democracy and devolution in Scotland), what began as physical forms of resistance to imposed national forms have now turned into cultural commodities with an ascribed political rhetoric.

This paper will discuss my upcoming fieldwork which uses multimodal methods to reassess individuals' engagement with these dances and to what extent they conform to elite narratives of meaning. Using theoretical ideas around phenomenology and affect theory, I hope to investigate dance as a useful locus for understanding nationalism as a lived identity, through attempting to let people's experiences and identities be expressed corporeally, rather than relying on ascribed political meaning to explain national identity.

KIRSTY KAY is a second-year, part-time $\mathrm{PhD}$ student in the Central and Eastern European Studies Department of the University of Glasgow. Her academic work focuses on the reinvention of traditions in national contexts in East and West Europe, using multimodal methodologies to elicit non-elite experiences of embodied nationalism. Kirsty also works as a freelance writer and editor and, having lived and worked in Central Europe and Scotland for over a decade, writes about both regions online.

\section{SUE SMITH}

\section{Dancing in the dark: described dances and unseen choreographies}

A visually impaired person attends a dance performance. What is the point? Sometimes theatres provide live audiodescription, via earpiece, commentating on what is seen. Through considering the history, philosophy and embedded ideology implicit in audio-description as a tool of access, this presentation asks: what makes a dance? What is being described? Tensions between what is described, listener 
expectations and who is 'interpreting' make this contentious territory.

Dissatisfied with the basic premise of an audio-description as translation of visual to verbal, I question how a critical appraisal of the current practice of audio description in dance, and the function of the audio describer can provide a foundation for new choreographies. I explore the artistic potential of access 'tools' as creative media in themselves and alternative approaches to what constitutes an experience of live dance performance. This presentation will reflect my search for alternative bodily presences in performance and new communicative processes which emerge out of the encounter between artistic production and social inclusion.

How can choreographic practices centralise a diversity of sensory perceptions as a steering artistic tool during the making of new work? Just as the ramp has become a design feature of award-winning recent architectures (think Tate Modern and Laban Centre, London), can access 'problems' allow cultures to think differently about who is participating in art? What kinds of new work can be created through an encounter between artistic production and social inclusion? Can new dance be made that doesn't need 'translating' at all?

SUE SMITH is a choreographer, Rayne Fellow (2006) and PhD candidate at Falmouth University. Her practice includes dance in elderly care, with cancer patients and Royal Marines. She believes that the potential for accessible, quality dance lies in the most unexpected places. She believes in reinterpreting 'dance' to reflect and reveal real lives across the broadest spectrum of experience. 


\section{LUCY AMSDEN}

\section{Ridiculous physicality in clown workshops at Ecole Philippe Gaulier}

Though the word 'clown' might conjure up a generic image, each clown student at the Ecole Philippe Gaulier looks different, wearing a costume that can elicit laughter or make their body ridiculous. My paper examines how students of the clown workshop develop ridiculous physicality, using the social exchange of laughter.

Clown physicality depends on contrast, partnerships and contradictions. A clown is a skilled performer, using physical skills in service of gags, with the direct intention of laughter. Ridiculousness is closely associated with ineptitude, and laughter can be generated by failure to function according to social expectations. As a result, clowning has the potential to highlight, challenge or enhance social norms. I explore this relationship using a case study of a clown act in Cirque du Soleil's Varekai, performed and directed by participants of Gaulier's workshop. This act includes a variety of physical and social ineptitudes and contrasts.

I explore the term 'ridiculous' to examine how clown performance has been understood as personal to the performer, in some way dependant on the performer's own body. I suggest that Gaulier teaches students to find what is ridiculous about their own body, or in other words, in what ways their body can be used to make people laugh. The social environment of the clown workshop is an international and multilingual one, which may have an impact on the extent to which physicality is used (more than language) to generate laughter. 
colloquia nationally, was part of the Performer Training Working Group in TaPRA 2013 at the Royal Conservatoire of Scotland, and performs in Glasgow and Edinburgh with Bright Club, presenting research through stand-up comedy.

HANDE GÜZEL

Fictive ability, fictive masculinity: gender and able-bodiedness in physical education classes in Turkey (1969-1983)

In the year 1969, a Ministry of Youth and Sport was established for the first time in Turkey, lasting until 1983. This institutional change on the surface reflected a discursive shift in terms of the state's relationship with the body. The interest in the body is reflected in physical education, yet physical education itself plays an active role in the definition and redefinition of the 'invested body', the body which is subjected to social controls and interventions (Harvey and Sparks, 1991). Based on this novel relationship, this paper concentrates on how physical education cuts across the categories of gender and disability in relation to the dominant and alternative conceptualisations of the body in that period in Turkey.

Based on a discourse analysis of primary sources related to physical education classes and policies, my preliminary results indicate that the physical education classes and the training of physical education teachers in this period strengthen hegemonic gender roles. While assigning particular activities to each gender, it also subordinates alternative femininities and masculinities. Furthermore, the physical education programmes display that the students are imagined as a group of 'fictive ability' (Galusca, 2009), as an extension of the nationalist goals behind physical education programmes. This ideology of the stateassuming that each citizen is able-bodied-not only further marginalises the disabled body, but also helps the state to exert further control on its citizens. Therefore, it is possible to call the disabled body the absent body, as it is not existent 
in written documents pertaining to this period.

Upon completion of her BA High Hons at the Department of Political Science and International Relations at Bogazici University in 2011, HANDE GÜZEL has worked as a Social Research Project Coordinator at a private research centre. In 2013, she joined the MA Comparative Studies in History and Society programme at Koç University, Istanbul, Turkey. Currently, she works as a research assistant at the same institution. Her Masters thesis investigates the conceptualisation(s) of the body and physical education through physical education classes that took place in Turkey between 1969 and 1983. Her research interests include sociology of the body, masculinity studies and disability studies.

\section{ANDRIA CHRISTOFIDOU}

\section{A historical account of genders in ballet}

Ballet, a dance genre with a long history, emerged as an activity by and for men. However, since the eighteenth century it has became an activity associated with women and femininity which has resulted in ballet's transformation into a low-status activity and profession. It turned into a scrutinised field for men to get involved in and those who chose to practice it often risked being characterised as feminine and/or homosexual.

This paper draws on data collected through the work of various dance historians and theorists (Burt, 2007; Daly, 1987; Hanna, 1988; Kraus, 1969) to give an overview of the alterations in Western theatrical dance between the sixteenth and twentieth centuries. It particularly describes the socio-cultural and economic conditions of that time and will refer to the most important transformations that affected ballet (among others, the introduction of point shoes and lighter costumes, the danseuse en travesti and the idea of narrative), to sociologically explain how they influenced the participation as well as representation of female and male dancers in dance performances. The talk presents how females were introduced and established into 
what used to be a male-dominated field, as well as how males slowly disappeared from it. Overall, this paper is a presentation of how the dance emerged in its various forms, how it resulted in what is today known as ballet, as well as how it became established as a female-concentrated, yet not dominated, activity and field.

ANDRIA CHRISTOFIDOU is a PhD candidate at the University of Glasgow looking at masculinities in the field of theatrical dance. She has a BA in Sociology and an MSc in Cultural Sociology. Andria is mostly interested in gender studies, masculinities/femininities, queer theory, cultural and dance sociology.

\section{JOSEPHINE LEASK}

\section{Shimmying hips and rotating wrists: the transformational room of the Bollywood dance class}

I participate in a local Bollywood dance class for mothers at my children's inner city London school. In this class, I am in a minority together with the teacher and one other mum, as being the only white, non-Muslim women. The majority of the other participants are migrant Bengali or Arabic women. In spite of our very different backgrounds and ages what we share in addition to being mothers is a joy of dancing, learning new choreography and sweating within the safe confines of a supportive group.

In this shared cultural space we are able to not only embody a variety of Indian, Arabic and Latin dance styles free from a critical eye or judgemental gaze, but also escape from the (often) disempowering environment outside.

Angela McRobbie (2005) argues that dance remains a complex and powerful manifestation of women's identity. The function of this class goes beyond that of an exercise class and establishes a nurturing place for female 
empowerment, identity formation and also pleasure experienced through the actual dancing. It also allows for cross-cultural sharing and a place in which community value and belonging can be experienced, as discussed by Sherril Dodds in her writing about the usefulness of diaspora studies in making sense of such cultural activities (2011). This Bollywood dance class challenges the notion of an amorphous, 'containing' multiculturalism (Bhabha, 1990) which suppresses unique identities and difference (Hall, 2003), through offering a place in which participants can embody and create diverse diasporic identities.

JOSEPHINE LEASK is a dance writer and lecturer with a background in performance, having worked as both a performer and devisor with a variety of choreographers and performance artists. She currently writes for londondance.com and is London correspondent for The Dance Insider as well as contributing to a variety of specialist dance books, academic and art publications. Each year she mentors aspiring dance writers who take part in Resolution Review! at The Place, London, and edits the online review magazine that covers the season. She is an associate lecturer on the BA (Hons) Contextual Studies programme at The London Studio Centre, Middlesex University, specialising in cultural studies and postmodernity.

\section{Acknowledgements}

The British Sociological Association, founded in 1951, is a registered charity (registered charity number: 1080235). The BSA is also a company limited by guarantee registered in England and Wales (company number: 3890729). www.britsoc.co.uk. 